https://doi.org/10.48009/2_iis_2007_547-553

\title{
AN INVESTIGATION OF THE FACTORS AFFECTING DATA WAREHOUSING SUCCESS
}

\author{
Roger L. Hayen, Central Michigan University, roger.hayen@cmich.edu \\ Cedric D.Rutashobya, Central Michigan University, rutas1cd@cmich.edu \\ Daniel E. Vetter, Central Michigan University, vette1de@cmich.edu
}

\begin{abstract}
The information technology (IT) implementation literature suggests that various implementation factors play critical roles in the success of an information system; however, there is little empirical research about implementation of data warehousing (DW) projects. DW has unique characteristics that may impact the importance of factors that apply to it. In this research effort, a case study is used to investigate a model of DW success. An IT staff at Financial Service Company (FSC) was also interviewed concerning the implementation factors and the success of the warehouse. The results from the case study and interview identified significant relationship among the system quality, data quality, perceived net benefits. It was found that management support and adequate resources help address organizational issues that arise during DW implementations; resources, user participation, and highly-skilled project team members increase the likelihood that DW projects will finish on-time, on-budget, and with the right functionality. The implementation's success with organizational and project issues, in turn, influences the system quality of the DW.
\end{abstract}

Keywords: Data warehouse success, data warehouse implementation, financial services

\section{INTRODUCTION}

Decision support systems (DSS) are an area of the information systems (IS) discipline that focuses on supporting and improving managerial decision making [1]. In terms of contemporary professional practice, DSS include personal decision support systems (PDSS), group support systems (GSS), executive information systems (EIS), online analytical processing systems (OLAP), data warehousing (DW), and business intelligence (BI). Over the three decades of its history, DSS has moved from a radical movement that has changed the way IS were perceived in business, to a mainstream commercial IT movement, in which all organizations engage [1].

Successfully supporting managerial decision making has become critically dependent upon the availability of integrated and high quality information organized and presented to managers in a timely and easily understood manner. DWs have emerged to meet this need. Surrounded by analytical tools and models, DWs have the potential to transform operational data into BI by effectively identifying problems and opportunities.

\section{Importance of the Study}

The development of large-scale EIS has created the need for continuous high-quality data regarding the operations of an organization. The bull market of the 1990s led to a plethora of mergers and acquisitions, and an increasing globalization of the world economy [1]. Large organizations were faced with significant challenges in maintaining an integrated view of their business. This was the environment of the birth of DW. During the mid-to-late 1990s, DW became one of the most important developments in the information systems field. It is estimated that 95 percent of the Fortune 1000 companies either have a DW in place or are planning to develop one [8]. In 2002, the Palo Alto Management Group predicted that the DW market would grow to a $\$ 113.5$ billion market, including the sales of systems, software, services, and in-house expenditures [8].

\section{Definitions}

A DSS is the computer systems, both software and hardware, that assist the user in complex problem solving or decision-making [15]. Within DSS, a DW is a repository of integrated information, available for querying and analysis [13]. Many DSS application require data regarding business and economic conditions. A DW provides a means for accessing and analyzing these data in the support of business decision making.

\section{Research Problem}

DW project is an expensive and risky undertaking [10]. The typical project costs over $\$ 1$ million in the first year alone. And, it is estimated that one-half to two-thirds of all initial DW efforts fail [19]. Determining factors affecting DW success are important in the deployment of this DSS technology by organizations. The literature review in the next section discusses several factors that affect DW success. Then, 
the research methodology is described, a research model is delineated, and the results are reported.

\section{LITERATURE REVIEW}

The literature review discusses the factors for the failure of DW success in great depth. A study by Briggs (2002) found three factors for the failure of DW success. These are environmental, project, and technical factors.

1. Environmental factors include company acquisitions and takeovers, change in business environment, regulatory changes, organizational politics, and lack of senior management support. Others include human error, corporate culture, organizational decision making, change management, and lack of business drivers.

2. Project factors include underestimating complexity and workload, high expense, lack of understanding of cost issues over time, difficulty in quantifying return on investment (ROI), and overselling benefits of DW. Others include the challenge of building a competent userdeveloper-management project team, lack of IS staff political savvy, long development and delivery timeframe, poor selection of products and end-user tools, and failure to manage the scope of the project.

3. Technical factors include lack of common data definitions across different business units, data quality, inefficient technology, data integration, and lack of clear understanding of DW applications and data needed.

Another study by Vassiliadis [18], discusses the factors for the failure of DW. Considering factor of failure is important in establishing undesired action for a success. According to him, a DW project is a great risk and is definitely endangered by several factors. These factors can be grouped into four categories, which are design, technical, procedural, and socio-technical. Each factor group is described as follows:

1. Design factors abide by no standard or even widely accepted metadata management techniques or languages, data engineering techniques, or design methodologies for DWs. Rather proprietary solutions from vendors or doit-yourself advice from experts seem to define the landscape.

2. Technical factors correlate to the gap that exists in the evaluation and choice of hardware components.

3. Procedural factors involve reasons for deficiencies concerning the deployment of the DW. Apart from classical problems in IS manage- ment, it is important to notice that the role of user communities is crucial. The end-user must be trained to the new technologies and included in the design of the warehouse.

4. Socio-technical factors converge on breaking the organizational treaties and are a consequence of the fact that the DW may reorganize the way the organization works and introduce the functional or subjective domain of the stakeholders. For example, imposing a particular client tool on users invades the users' desktop, which is considered to be their personal territory.

Problems due to data ownership and access are grouped into two categories. First, data ownership is power within an organization. Any attempt to share or take control over somebody else's data is equivalent with loss of power of this particular stakeholder. Second, no division or department within an organization can claim to possess $100 \%$ clean, error-free data [18]. According to the study by Watson [19], the most common factors for the failure of a DW success include weak sponsorship and management support, insufficient funding, inadequate user involvement, and organizational politics.

\section{METHODOLOGY}

This research is carried out using a case study approach. The case study is valued as a research method for its capacity to examine a phenomenon in its real-life context [4]. A great strength of this method is its facility for retaining and exploiting the richness of the situation. Because of the suitability of the case study to deal with poorly structured, lightly researched problem domains, it has been judged as well suited to the exploratory phase of an investigation. However, the case study can be shown to be well suited to descriptive and explanatory research as well. Here, the case study method is used for exploring, describing, and creating a research model focusing on factors affecting DW success.

The case study is conducted at Financial Service Company (FSC), which is headquartered in the southeastern United States. FSC is a leading marketer of investment products and processor of healthcare payments. It has approximately 7,500 employees and operates in six southern and southeastern states. The case study provides a description of the success that FSC achieved from DW implementation. Data describing experiences at FSC were gathered from a telephone interview with an IT staff most closely involved in the decision to implement DW. Apart from the telephone interview, in-depth research has also been conducted on the successes of FSC as a result of deploying a DW. A research model is de- 
veloped to investigate the factors affecting DW success. This model serves as a guide in data gathering regarding DW success. The nature of case study research is such that employing a guide to data gathering can provide a focus without inhibiting unnecessarily the discovery of unexpected phenomena.

\section{RESEARCH MODEL}

Researchers have investigated the success of information systems (IS) in numerous ways [9], such as by measuring the satisfaction of users, service quality, and the perceived usefulness of specific applications. Researchers treat IS success as a multi-faceted construct and select several appropriate success measures based on the research objectives and the phenomena under investigation. These provide possible relationships among the success dimensions when constructing a research model. That model establishes a framework for metrics that can be used to manage a DW implementation project to help insure its success.

\section{Investigation Before Creating a Research Model}

To develop the research model, the IT implementation, infrastructure, and DW literature were reviewed to identify factors that potentially affect DW success. After the literature review, the case study was conducted at FSC, as mentioned earlier. The findings from the case study, together with the literature review, were used to create a research model, and to structure the interview with IT staff at FSC most closely involved in the decision to implement DW. The interview substantiated that the research model contained appropriate factors and relationships among the model's factors. Minor changes were incorporated into the model based on the interview. Figure 1 presents the resulting research model. The rationale for the factors and the relationship among the factors are described in the following sections.

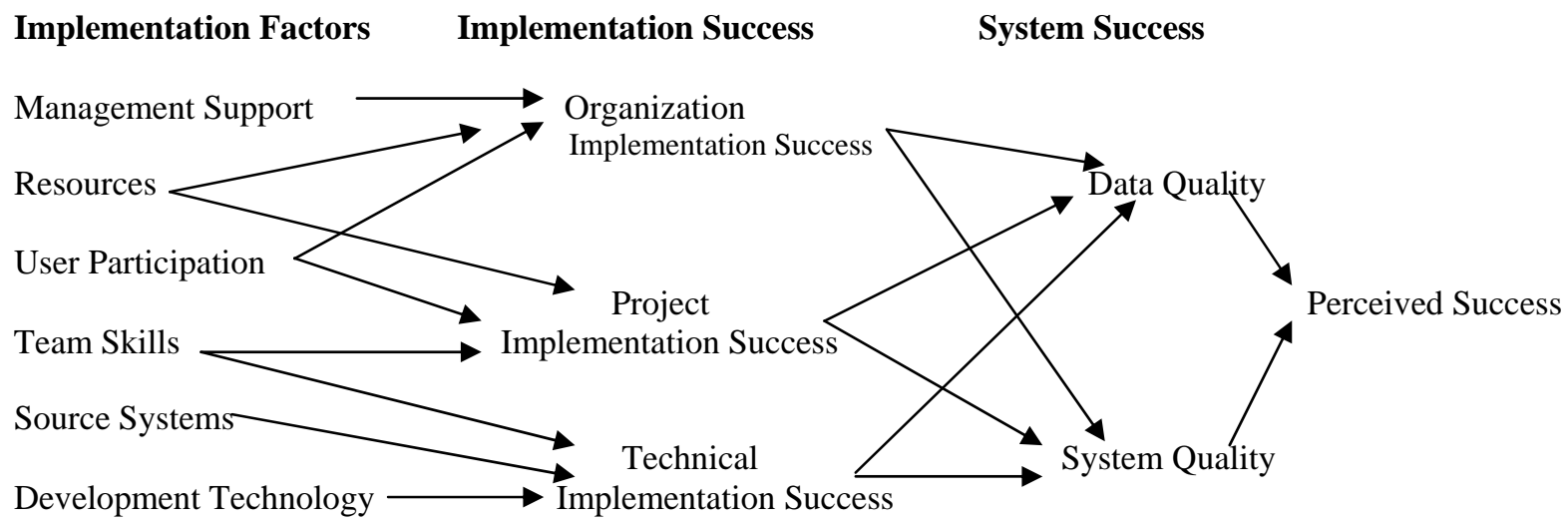

Figure 1: Research Model for Data Warehousing Success

\section{Research Model Description}

As illustrated in Figure 1, implementation factors drive implementation success that leads to system success for a DW implementation. The implementation factors are distilled from the literature search. These are clustered into the primary drivers of management support, resources, user participation, team skills, source systems, and development technology. The drivers, for which metrics can be established and monitored, impact the DW implementation success. Implementation success is subdivided into three key components. These include success with organizational, project, and technical issues that arise during the lifetime of the DW project. Those successes influence the data quality and system quality, which guide the system success culminating in the per- ceived success of the overall DW implementation. Hence, implementation success means that the project team has persuaded the organization to accept DW, completed the DW according to plan, and overcome technical obstacles that develop. The implementation success in turn affects the system success, defined as the perceived quality of the DW system including the data it contains. This impacts the perceived net benefits or ROI from the deployment of the DW in business decision making. In this manner, a framework for overall DW project management schema is established. In this framework, the perceived success is ultimately driven by the implementation factors of the model. As a result, each of those factors is consider next in more detail. 
Management support is widespread sponsorship for a project across the management team and consistently is identified as one of the most important factors for DW success. It motivates people in the organization to support the DW initiative and the organizational changes that inevitably accompany it [19]. Management support can overcome political resistance and encourage participation throughout the organization [14]. It has been found to be important to the success of many kinds of IT implementations, especially with various DSS.

Resources include the money, people, and time that are required to successfully complete the project. Studies have found that resource constraints have a negative effect on successful system design and implementation [16]. Resources are likely to be important to DW projects because they are expensive, timeconsuming, and resource-intensive initiatives [17]. Providing adequate resources usually lead to a better chance of overcoming organizational obstacles and communicating high levels of organizational commitment. Resources also can help project teams meet their project milestones and benchmarks.

User participation occurs when end users are assigned project roles and tasks, which leads to better communication of their needs and helps ensure that the system is implemented successfully [12]. When users participate in DW projects, they have more realistic expectations about what the warehouse will provide, which makes them more likely to accept the DW when it is delivered. Users also help the project team stay focused on the real requirements and needs of the user community when they participate on the project team throughout the implementation.

People are important when implementing any IS and this is also true for a DW project. The human resource component directly affects project success or failure. In particular the skills of the DW development team have a major influence on the outcomes of the warehouse project [3]. Team skills include both technical and interpersonal abilities. A team with strong technical and interpersonal skills is able to better perform tasks and interact with end users. The skills of development team members have been traced to IT implementation success. Only a high quality, competent technical team can identify the requirements of complex DW projects. This mix of skills should help warehouse projects to more successfully meet their objectives at a project level, and it should be of great value when technical obstacles need to be overcome. A highly skilled project team should be much better equipped to manage and solve technical problems.
A primary purpose of DW is to integrate data throughout the organization; however, data often resides in diverse, heterogeneous sources [3]. Each unique source requires specialized expertise and coordination to access the data. Further, the data that exist often are defined differently across sources, making it quite challenging for the project team to properly reconcile and load the data into the warehouse. Standardized data can result in easier data manipulation, fewer problems, and ultimately, a more successful system [5]. Thus, the quality of data sources depends on the standardization of an organization's technology and data.

Development technology is the hardware, software, methods, and programs used in completing a project. The development tools that a project team uses can influence the effectiveness of the development effort as much as other factors, such as people. The tools can impact the efficiency and effectiveness of the development team, especially if they are not well understood or easy to use [2]. The development tools needed to build a DW are different from those used with operational systems because warehousing requires sophisticated extraction, transformation, and loading software; data cleansing programs, database performance tuning methods; and multidimensional modeling and analysis tools. If the development technology does not meet the needs of the project team or work well with the legacy systems, the DW implementation can suffer [19].

\section{RESULTS}

The case study found that data quality and system quality had important relationships with perceived net benefits and explained a good portion of the model's variance. The quality of the DW and the data that it provides are associated with the net benefits as perceived by the organization's data suppliers and users. In other words, a warehouse with good data quality and system quality improves the way data is provided to decision support applications and decision makers. System quality and data quality do affect perceived net benefits or ROI in the context of DW. More work is needed, however, to examine exactly how the dimensions of success interrelate. Theoretically, there is a need to understand why relationships exist, whereas practically, there is a need to explore how success measures can be applied most effectively. There is also a need to explore the role of other success dimensions, such as extent of implementation or use, in a DW context.

\section{Implementation Factors for Data Warehousing}

Management support and resources are key ingredients to the acceptance of a DW by an organization. 
This finding is consistent with other IT implementation studies and substantiates their value in DW projects. A DW is an expensive undertaking that takes a long time to initially develop, and it is an enterprisewide endeavor with significant organizational impacts. DW creates changes that resonate throughout the entire organization, and it demands broad-based and lasting support. Together, the two organizational factors were found to be important in the research model, and together they provide organizations with effective mechanisms for increasing widespread support for warehousing, addressing politics, and managing change effectively.

According to the findings, the availability of adequate resources, appropriate people on the project team and user participation have positive effects on the project's outcome. Unfortunately, these are areas in which companies sometimes experience problems. DW demands a large financial investment that can be tough to sell to management without having guaranteed up-front tangible benefits. Currently, the demand for experienced DW personnel exceeds the available supply, and many companies have little choice but to staff from within, independent of whether the experience of their people is ideal. As a result, the DW staff may have little or no experience in how to plan for and manage a project of this type. User participation also can be challenging because of the many, diverse internal groups (e.g., marketing and production) whose needs must be understood and communicated to the project team. Much of the DW literature advocates an incremental approach when building a warehouse, which means building a warehouse in three to six month increments that each produces substantial value to the business. In this way, project teams can work towards goals that are more manageable in size, users can participate in only relevant parts of the project, and management can be satisfied that the project is delivering value. In fact, if management is extremely finance-oriented, the value that is created during beginning increments can be used as a foundation for a rigorous future cost benefit analysis.

Technical factors also affect DW implementations. The practitioner literature contains considerable debate over the merits of beginning a decision-support infrastructure with an enterprise-wide DW versus a smaller-scale data mart. The DW proponents argue that data marts can quickly grow into a mass of information silos that counter the underlying purpose of DW; whereas data mart supporters explain that DWs are more expensive and difficult to construct in a reasonable amount of time, and a data mart provides a proof of concept. This study indicates that more technical problems are related to warehouses that pull from diverse, nonstandard sources, undoubtedly due to the increased technical complexity. Organizations involved in building enterprise-wide DWs should prepare for technical obstacles that must be overcome. The development technology that is used also appears to affect the technical problems that may arise during implementation. DW requires specialized software, and the project team must learn how to use this software and how to fit it into the existing technical environment.

Interestingly, although the source systems and development tools are related to the technical problems that occur during the development of a warehouse, the technical problems do not have long-lasting effects that ultimately affect the benefits from operational warehouses. Likely, project teams are able to address technical problems effectively, much more so than they are able to overcome organizational and project issues.

\section{Interview and Case Studies}

The impact of DW can be very positive, especially based upon the evidence in the financial services industry. For example, the success of an actual DW implementation at FSC, Inc. was very dependent upon the firm's deployment decisions [7]. It is not only the DW technology itself that creates benefits; it is the implementation decisions and proper transformation of the organization that is key.

In an interview with a key employee of the same firm, C. Heagerty, (personal communication, November 10, 2006), an IT staff at FSC, Inc., the company realized that at the time it needed a long-term strategy if it was to survive in the increasingly competitive banking industry. FSC needed to identify a marketing niche in which it could excel. The strategy selected was to be customer intimate, that is, to know its customers exceptionally well. The name given to this strategy was tailored client solutions (TCS). It was based on the premise that products tailored to customers' needs would lead to stronger customerbank relationships and long-term sustainable profits. Financial products, distribution channels, sales, and servicing would be integrated in ways designed to meet clients' needs and preferences while achieving target profitability levels. The data needed to implement TCS would be provided by a DW.

Other financial services firms have benefited from DW as well. The implementation of a DW initiative at a credit card servicing firm was also successful. Staffing costs were significantly reduced by shifting more manual labor intensive processes to more efficient automated processes. [11]. DW has also allowed financial services firms to become more cus- 
tomer oriented and improve the firm's performance. [19].

\section{SUMMARY AND CONCLUSION}

There are few empirical studies on DW. A valuable contribution of this study is the extension of the IS implementation literature through the investigation of DW implementation factors. Both IS implementation and DW areas benefit from the validation of current understanding and the development of new ideas.

\section{Findings}

The findings suggest that most of the traditional factors from the implementation literature (e.g., management support and resources) also affect the success of a DW, thus providing further evidence of the existence of a common set of IT implementation factors. However, the study also shows general IT implementation success models cannot be used to investigate DW without some modification. For example, other factors were needed to explain the data quality and system quality for the DW.

The implementation success model provides a framework for the metrics of a DW implementation project. Metrics for each of the implementation factors (Figure 3 above) can be specified in more detail and benchmarks established for the DW implementation project. These drivers for project success can be measured and compared with the established project benchmark to bolster overall project management.

Another contribution of this study is the way in which implementation success factors can be grouped together into organizational, project, and technical success to more clearly communicate the kinds of effects implementation factors can have. This approach supports tying implementation factors to system success and the benefits from the ultimate use of a system. The empirical evidence supports the idea that these connections are important to understand.

The case study clearly identifies a business sector that can benefit from the deployment of DW. As the research indicates, organization in the financial services sector can benefit from the successful application of DW.

\section{Future Research}

More research is required to further develop an understanding of infrastructure and determine the difference between infrastructure and application-level IT phenomenon. This study presents DW a viable way of investigating such issues. Further, the study challenges the notion of applying IT implementation knowledge to an infrastructure context without giving careful thought to how changes should be made.
However, both the IS implementation and DW areas will benefit from the validation of current understandings and the development of new ideas, respectively, with the hope that this investigation will increase the interest in DW research on IS and guide others in new investigations.

\section{REFERENCES}

1. Arnott, D. and Pervan, G. (2005). A Critical Analysis of Decision Support Systems Research. Journal of Information Technology, 20(2), pp. $67-85$.

2. Banker, R. D., and Kauffman, R. J. (1991). Reuse and Productivity in Integrated ComputerAided Software, MIS Quarterly, 15(3), pp. 375 402.

3. Barquin, R. C., and Edelstein, H. (1997). Planning and Designing the Data Warehouse, Upper Saddle River, NJ: Prentice Hall.

4. Benbasat, I., Goldstein, D. K., \& Mead, M. (2000). The CASE Research Strategy in Studies of Information Systems. MIS Quarterly, 11(3), pp. 369 - 386.

5. Bergeron, F., and Raymond, L. (1997). Managing EDI for Competitive Advantage: A Longitudinal Study," Information \& Management, 3(1), pp. 319 - 333.

6. Briggs, D. (2002). A Critical Review of Literature on Data Warehouse Systems Success/Failure. Journal $f$ Data Warehousing, 49(3), pp. $1-20$.

7. Cooper, L., Watson, H., Wixom, B., and Goodhue, D., (2000), Data Warehousing Supports Corporate Strategy at First American Corporation, MIS Quarterly, 24(4), pp. 547-567.

8. Eckerson, W.W. (2003). Evolution of Data Warehousing: The Trend toward Analytical Applications. Journal of Data Warehousing, 25(1), pp. 1-8.

9. Garrity, E. L. and Sanders, G. L. (2001). Information Success Measurement. Hershey: Idea Group Publishing.

10. Grim, R., and Thorton, P. (2001). P. A Customer for Life: The warehouse Approach. Journal of Data Warehousing, 2(1), pp. 73-79.

11. Hackathorn, R., (2002), Current Practices in Active Data Warehousing, Bolder Technolgy Inc., pp. 11-13.

12. Hartwick, J., and Barki, H. (1994). Explaining the Role of User Participation in Information System Use, Management Science, 40(4), pp. $440-465$.

13. Inmon, W. H. (2002). Building the Data Warehouse ( $3^{\text {rd }}$ Ed.). New York: Wiley. 
14. Lawrence, M., \& Low, G. (1993). Exploring Individual User Satisfaction within User-Led Development, MIS Quarterly, 17(2), pp. 195 208.

15. Newman, S., Lynch, T., and Plummer, A. A. (2000). Success and Failure Decision Support Systems: Learning as We Go. Journal of American Society, 21(3), pp. 1 -11.

16. Sakaguchi, T., and Frolick, M. N. (1997). A Review of the Data Warehousing Literature, Journal of Data Warehousing, 2(1), pp. $34-54$.

17. Tait, P., and Vessey, I. (1988). The Effect of User Involvement on System Success: A Contingency Approach, MIS Quarterly, 12(1), pp. $91-108$.

18. Vassiliadis, P. (2004). Gulliver in the land of data warehousing: practical experiences and observations of a researcher. Journal of Data Warehousing, 2(3), pp. $1-16$.

19. Watson, H. J., and Haley, B. J. (2004). Data Warehousing: A Framework and Survey of Current Practices, Journal of Data Warehousing, 2(1), pp. $10-17$.

Acknowledgement. We would like to thank Christopher D. Heagerty from Financial Service Company (FSC), for his personal interview regarding factors affecting data warehousing success at his organization. 